\title{
Medical anthropology
}

\section{Medicos viajeros Boliviaros}

$\mathrm{D}$ eep in Andean valleys on the Bolivian side of Lake Titicaca live groups of indigenous healers, the Callahuaya. Herbalists, naturalists and magical healers, they travel by foot throughout Bolivia, Peru, Northern Chile and Argentina, where they are known far and wide as medicos viajeros Boliviaros (Bolivian travelling doctors).

Callahuaya carry the tools of their trade in beautiful hand-woven bags (chuspas), which are skillfully made by their wives on primitive backstrap looms, using alpaca, llama and sheep's wool that is dyed using local plants and insects. The intricate stripes and curlicues on chuspas designate their owner's rank and experience in the healing hierarchy, from basic healer to those of the highest stature. In addition, the brilliantly dyed chuspas are often adorned with exotic anthropomorphic and zoomorphic healing symbols representing humans, horses, llamas, rodents, birds, fish, deer, dogs and bulls.

Not to be outdone, Callahuaya wives wear exquisitely woven head bands, or winchas, with similar figures and edged with tiny glass beads. Healers' wives are expected to remain faithful during their husband's healing journeys, which last many months, and were traditionally thrown off a precipice if they succumbed to sexual temptation.

Within the healer's chuspas are a most interesting assortment of roots, resins, feathers, animal glands and amulets, used to induce love and wealth. More importantly however, is their wide assortment of pharmacologically active plants such as coca and quinine. Traditional stories tell of the Callahuaya bringing quinine to the labourers constructing the Panama Canal, who were suffering from malaria. Mineral and coal miners in southern Bolivia and Peru were administered cocoa leaves to chew to invigorate them in their exhausting and back-breaking work in the frigid, high-altitude mines.

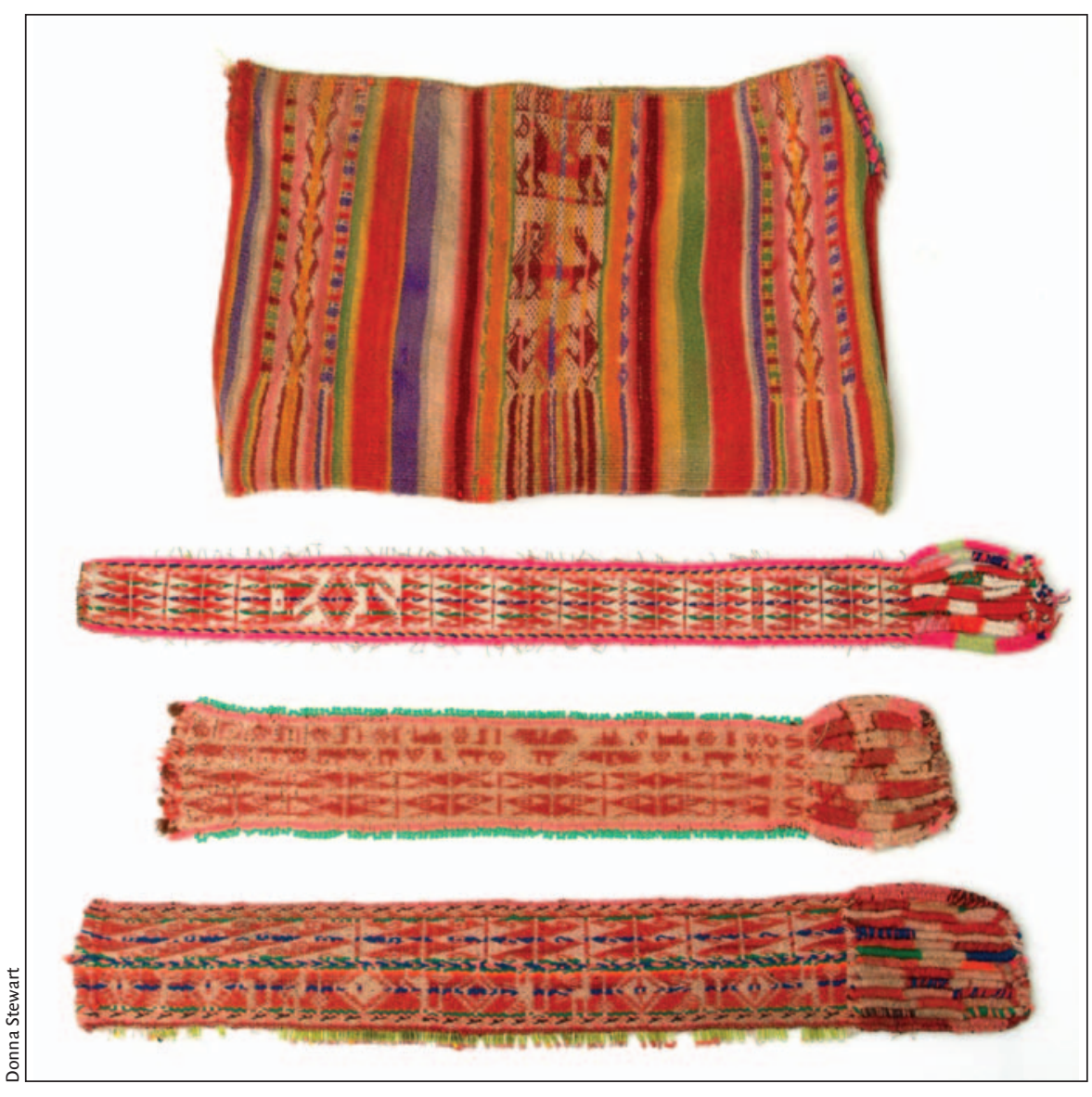

This early 2oth century chuspa (top) features a man, horse, llama and 3 vizcachos (rodents). The red lines of downward pointed arrows on either side, indicate the healer is of intermediate general rank. The top wincha (headband) depicts horses flanking a magical eye (nawa)," the middle one features small animals and bulls and the bottom one depicts condors and nawas.

The Callahuaya recognize 2 origins of illnesses: mystical and natural. Mystical illnesses are cured by magic and witchcraft, while natural illnesses are more likely to be cured by herbs. Various leaves, roots, seeds, flowers and nuts are administered as stimulants, anesthetics and analgesics, either in dried form or as potions. Their healing rites are thought to originate in pre-Hispanic times. The Callahuaya's secret ceremonial language is said to have been learned from the Inca kings. Healing ceremonies are often accompanied by fire, water, chants, dancing and the lay- ing on of hands in which mother earth (Pachamama), water, fire and mountains are venerated.

For thousands of ill and distressed rural Andean indigenous people who live in abject poverty, the Calluhuaya offer hope, traditional remedies and knowledge, kindness and more than a little healing success.

\section{Donna E. Stewart MD \\ Professor and Chair of Women's \\ Health \\ University of Toronto \\ Toronto, Ont.}

